\title{
The Effect of Atmospheric Plasma on the Perception of Taste and Mixability of Powdered Whey Protein Isolate
}

\author{
Heidi Lightfoot
}

Clinical Research Physician, Basingstoke and North Hampshire Hospital, England Email: heidi.lightfoot@gmail.com 


\begin{abstract}
:
Powdered whey protein is most often used as a food supplement to enhance athletic performance, but it also has a role in health and wellness as well as the pharmaceutical sectors. Given the dynamic array of roles across several industries, understanding the functional characteristics of whey proteins is of great interest. Protein structure can be altered via plasma-surface modification (PSM), a method which is based on plasma as a means to alter a material's surface structure and as such its functional characteristics. So far PSM has been utilized to alter the surfaces of inorganic materials but there is growing interest in its applications with organic materials such as food proteins. To date, the effect of atmospheric plasma on the perception of mixability and taste of whey protein isolate has not been explored; the purpose of this study is to investigate whether PSM could be effectively utilized to alter the two. Psychometric measures of mixability and taste were gathered during a single-blind, randomized clinical trial design during which subjects ingested $28 \mathrm{~g}$ of either PSM treated or untreated whey protein isolate powder. A $30.26 \%$ increase in perceived mixability and $12.5 \%$ in perceived taste were observed upon treatment with PSM, indicating that plasma treatment does not negatively impact the perception of mixability and taste of whey protein isolate and under the right conditions could promote an improvement in these characteristics.
\end{abstract}

\title{
Figures:
}


A.

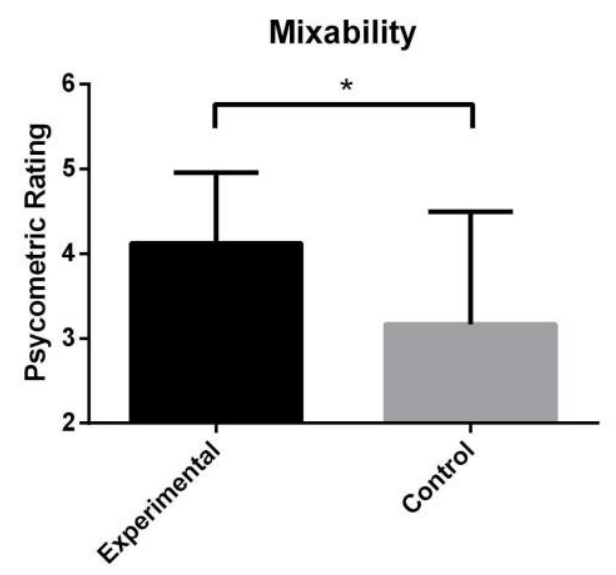

B.

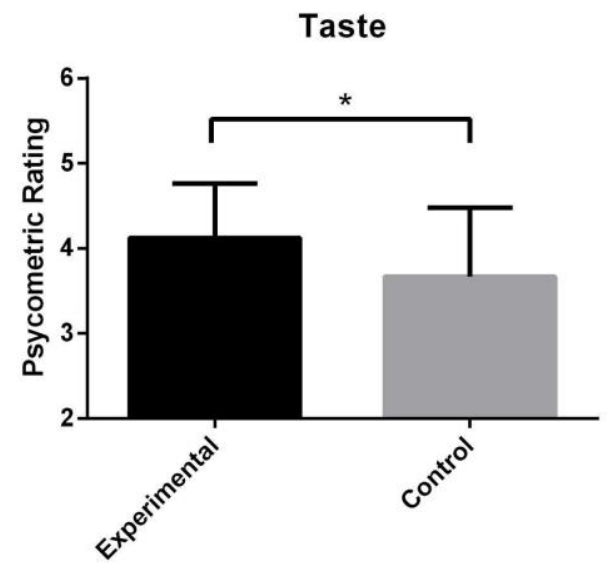

Figure Legend:

Figure A: Comparison of mixability perception of untreated and plasma-treated whey protein powders. Asterisk $\left(^{*}\right)$ indicates $30.26 \%$ increase in mixability with PSM treatment as compared to untreated control $(p=0.0614)$.

Figure B: Comparison of taste perception of untreated and plasma-treated whey protein powders. Asterisk ( $\left(^{*}\right)$ indicates $12.5 \%$ increase in taste with PSM treatment as compared to untreated control $(p=0.1305)$.

\section{Introduction:}

Whey was discovered 5000 years ago and was initially considered an effective medicinal treatment for common illnesses. ${ }^{1}$ Since those times, whey has generally been disposed of as a waste product of casein, yogurt and cheese production. ${ }^{1}$ However, advancements in processing and handling techniques enabled the isolation of whey from milk, and it is nowadays recognized as one of the most nutritionally available protein products on the market. ${ }^{1,2}$ Along with the progress in scientific knowledge of whey protein structures and 
functions, technological, engineering and processing advancements have enabled costeffective and efficient whey manufacture and have as such contributed to its availability and commercialization. Functional and bioactive whey is attractive due to its biological, chemical, physical and nutritional characteristics, all of which enable its applications as a food and nutrition product. ${ }^{2}$ Whey is commonly used as a dietary supplement either to enhance athletic performance or improve weight management efforts. It has also been used as an emulsifier or flavor and texture enhancer in the food and nutrition industries.

The processing and handling of whey has been reported to cause flavor variations between whey protein products $^{3}$, and the flavor of whey solids has been a limiting factor in their use in food products. ${ }^{3-7}$ Off-flavors such as bitterness, sourness, diacetyl and 'brothy' have all been mentioned as confounding factors in the lack of the use of whey proteins in bland or neutral food products. ${ }^{3,8,9}$ Previous findings report that composition, manufacturing process and storage all affect the taste of different milk protein products. ${ }^{10}$ In particular, shipping and storage temperatures have been implicated in the final outcome of protein flavors as well as their durability or shelf-life. ${ }^{10}$

Plasma-surface modification (PSM) is a method that relies on plasma, a gas that is characterized by both high conductivity as well as high internal energy ${ }^{11}$, to induce changes in the chemical properties of materials. Plasma treatment is said to be initiated when plasma ions come into contact with a particular surface and induce changes in surface area and hydrophilicity. ${ }^{11}$ Furthermore, atmospheric plasma treatment takes place if one of the several treatment gases that are used during PSM is atmospheric air. ${ }^{12}$ PSM is a frequently used tool for the modification or functionalization of surface structures of interest, yet atmospheric plasma as a means to induce whey protein changes that potentially affect the perception of end user characteristics such as mixability and taste has not been investigated to date.

\section{Objective:}

The goal of this study is to investigate whether protein structural alterations by atmospheric plasma also modify the taste and mixability perception of dry powdered whey protein isolate.

\section{Results \& Discussion:}

Here we investigate the impact of PSM on dry powdered whey protein isolate and its effects on two of the most important end user characteristics, whey protein mixability and taste. Proprietary PSM technology (Ingredient Optimized ${ }^{\mathrm{TM}}$, Plasma Nutrition, USA) was used to effectively mediate the exposure of organic dry powder materials to plasma to elicit multiple changes, including protein structure alterations. A commercially available dry powder whey protein isolate was obtained as source material, part of which was PSM treated and another part from the same batch served as the control for the experiment. 
Participants' psychometric ratings were utilized to measure mixability and taste perceptions of the tested protein batches, and an increase in both variables was observed. An overall $30.26 \%(p=0.0614)$ enhancement in mixability (Figure A) and a $12.5 \%(p=0.1305)$ improvement in taste perception are reported. While the $p$-values are not below the cut-off used to indicate statistical significance, these findings can be considered as relevant in light of a few points. The low number of participants is a confounding factor affecting significance but not the overall perceptions of mixability or taste in a negative way. In other words, while the p-values do not meet the cut-off criteria, the degree to which mixability and taste were perceived did not decrease. This implies that PSM did not have a negative effect on either mixability or taste, and thus it can be concluded that the trends of our findings are such that an increase in participant number would not only result in an increase in positive end user perception percentages for both characteristics, but that the findings would also be statistically significant. Ultimately, further investigations with more participants are warranted to confirm these speculations.

Pre-treatment procedures have been suggested as means to overcome the negative flavors of whey proteins that are caused by their processing and handling prior to release. ${ }^{13}$ Here we analyze the effects of PSM on perceived flavor and mixability, and our findings indicate a positive correlation between important end user perceptions and the use of plasma on whey protein isolate powder. Overall, these findings indicate that plasma is an effective treatment method of dry powdered whey as means to increase important end user perceptions. This would be of great interest to food and nutrition industries in their efforts to optimize whey protein powder flavors as well as solubilities.

\section{Conclusions:}

Taste and mixability are two of the most important end user perceptions for a commercial protein application. PSM seems to have no negative effects on either taste or mixability and may even enhance these qualities. In fact, a $12.5 \%$ increase in taste perception and a $30.26 \%$ increase in mixability perception were observed. These findings have several inferences for the use of PSM to enhance commercially available whey protein powders that could be of particular interest to the food and nutrition industries.

\section{Methods:}

A single-blind, randomized clinical trial design study was conducted including 14 participants, out of which eight received $28 \mathrm{~g}$ of PSM-treated whey protein powder per day and six received $28 \mathrm{~g}$ of untreated whey-protein powder per day for a total of eight weeks.

Both groups received a commercially available dry powdered whey protein isolate from the same batch. The experimental group received material that had been exposed to atmospheric plasma conditions using the Proprietary PSM technology (Ingredient 
Optimized $^{\mathrm{TM}}$, Plasma Nutrition, USA) technique described above, and the control group received unexposed material from the same batch.

Psychometric measures of the protein's taste and mixability following its ingestion were gathered during the trial.

Statistical analysis was conducted via Prism 6 (GraphPad Software) using a one-tailed ttest $(p<0.05)$.

\section{Limitations:}

This study investigated the application of PSM on only one source of dry powdered whey protein isolate. While the whey protein isolate source material used in this investigation is commonly found in commercial use, there may be variations between the material used and other market-available whey protein isolate powders. Further studies are needed to examine the effect of PSM on a range of dry powder whey protein isolate sources.

\section{Funding Statement:}

This work was financially supported by Plasma Nutrition.

\section{Ethics Statement:}

No fraudulence is committed in performing these experiments or during processing of the data. We understand that in the case of fraudulence, the study can be retracted by Matters. This study was approved and conducted in compliance with Institutional Review Board guidelines.

\section{Sources:}

1. Smithers, G.W. (2015). Whey-ing up the options-Yesterday, today and tomorrow. International Dairy Journal, 48, pp.2-14. DOI: 10.1016/j.idairyj.2015.01.011

2. Smithers, G.W. (2008). Whey and whey proteins-from 'gutter-togold'. International Dairy Journal, 18(7), pp.695-704. DOI: 10.1016/j.idairyj.2008.03.008

3. Whetstine, M.C., Croissant, A.E. and Drake, M.A. (2005). Characterization of dried whey protein concentrate and isolate flavor. Journal of dairy science, $88(11)$, pp.3826-3839. DOI: 10.3168/jds.S0022-0302(05)73068-X

4. Mortenson, M.A., Vickers, Z.M. and Reineccius, G.A. (2008). Flavor of whey protein concentrates and isolates. International dairy journal, 18(6), pp.649-657. DOI: 10.1016/j.idairyj.2007.12.003

5. Hugunin, A.G. (1987). Applications of UF whey protein: developing new markets [ultrafiltrated whey]. International Dairy Federation. 
6. Livney, Y.D. and Bradley Jr, R.L. (1994). Factors affecting flavor of whey as an ingredient in ice cream and other frozen desserts. Cultured dairy products journal (USA).

7. Morr, C.V. and Ha, E.Y.W. (1993). Whey protein concentrates and isolates: processing and functional properties. Critical Reviews in Food Science \& Nutrition, 33(6), pp.431-476. DOI: 10.1080/10408399309527643

8. McGugan, W.A., Larmond, E. and Emmons, D.B. (1979). Some observations on the flavor of acid whey. Canadian Institute of Food Science and Technology Journal, 12(1), pp.32-35. DOI: 10.1016/S0315-5463(79)73033-1

9. Chen, X.D. and Stevenson, R.J. (1998). Headspace sampling of whey protein concentrate solutions using solid-phase microextraction. Food Research International, 31(5), pp.371-379. DOI: 10.1016/S0963-9969(98)00098-2

10. Wright, B.J., Zevchak, S.E., Wright, J.M. and Drake, M.A. (2009). The impact of agglomeration and storage on flavor and flavor stability of whey protein concentrate $80 \%$ and whey protein isolate. Journal of food science, $74(1)$. DOI: 10.1111/j.1750-3841.2008.00975.x

11. Chu, P.K., Chen, J.Y., Wang, L.P. and Huang, N. (2002). Plasma-surface modification of biomaterials. Materials Science and Engineering: $R$ : Reports, 36(5), pp.143-206. DOI: 10.1016/S0927-796X(02)00004-9

12. Shenton, M.J. and Stevens, G.C. (2001). Surface modification of polymer surfaces: atmospheric plasma versus vacuum plasma treatments. Journal of Physics D: Applied Physics, 34(18), p.2761. DOI: 10.1088/0022-3727/34/18/308

13. Morr, C.V. and Ha, E.Y.W. (1991). Off-flavors of whey protein concentrates: A literature review. International Dairy Journal, 1(1), pp.1-11. DOI: 10.1016/09586946(91)90024-3 